\title{
GESTATIONAL AND NEURODEVELOPMENTAL EFFECTS OF BLACK MUSTARD SEEDS' (BRASSICA NIGRA) EXTRACT IN WISTAR RATS
}

Bernard Ufuoma Enaibe 1, 2, Tolulope Timothy Arogundade 1, 2, Oluwaseun Adigun 2, Foyeke Munirat Adigun², Emmanuel Olusola Yawson 1, 2

${ }^{1}$ Department of Anatomy, Faculty of Basic Medical Sciences, Adeleke University, Nigeria

${ }^{2}$ Department of Anatomy, Faculty of Basic Medical Sciences, University of Ilorin, Nigeria.

Correspondence to Tolulope Timothy AROGUNDADE, Department of Anatomy, Faculty of Basic Medical Sciences, Adeleke University, P.M.B 250, Ede, Osun State, Nigeria. Tel: +2348037165263 Email: arogundadetolulope@gmail.com

\begin{abstract}
This study investigated the effect of the crude aqueous extract of Brassica nigra (Black Mustard Seeds) in gestation and on the prefrontal cortex of newborn Wistar rats at different doses following prenatal administration. Eighteen (18) adult female rats weighing an average of $180 \pm 10 \mathrm{~g}$ were used. The female rats were split into 3 groups of six animals; Group A received distilled water throughout gestation, Group B received $200 \mathrm{mg} / \mathrm{kg}$ body weight of extract throughout gestation, and Group C received $100 \mathrm{mg} / \mathrm{kg}$ body weight of extract throughout gestation). Rat pups from the experimental groups were sacrificed on postnatal days $1,7,14,21,28$, and 35 and subsequently prepared through routine histological and histochemical procedures. Brassica nigra was abortifacient at $200 \mathrm{mg} / \mathrm{kg}$ body weight and reduced litter size at $100 \mathrm{mg} / \mathrm{kg}$ body weight. No observed physical deformities in pups of treated groups. Comparative prefrontal microarchitecture revealed little to no alteration in the treated group. This study concludes that Brassica nigra (black mustard) is not totally innocuous and as such, should be moderately consumed or totally avoided in pregnancy.

Keywords: Brassica nigra; Mustard seeds; Gestation; Neurodevelopment.
\end{abstract}

\section{INTRODUCTION}

Changes in brain anatomy and functional connectivity are associated with several neurodevelopmental and neuropsychiatric disorders (Bellani et al., 2011). Many of these alterations in the brain are believed to precede disease onset and be causally related to disease symptoms and severity (vulnerability hypothesis) (Gilbertson et al., 2002). While brain development may begin from a so-called genetic blueprint, it is the overlay of experience on this blueprint that shapes development and leads to either normal structure and function or altered susceptibility for psychopathology (Andersen, 2003). The critical period is a time in the early stages of development of an organism during which it displays a heightened sensitivity to certain environmental stimuli, and matures in certain ways due to experiences at this time. If the organism does not receive the appropriate stimulus during this "Critical Period", it may be difficult, ultimately, less successful or even impossible, to develop some functions later in life (Siegler, 2006). Thus, brain development is a product of dynamic, bidirectional interplay between the individual's genotype, acquired at conception and the nature of the early environment, extending from intra-uterine to post-uterine consequences (Gluckman \& Hanson, 2004; Swanson \& Wadhwa, 2008).

Mustard seeds are the tiniest part of the mustard plant which flourishes in the cold weather, moist soil and general temperate conditions. The plant 
grows as a shrub while the seeds are about two millimeters in diameter and used as spices in many countries. There are approximately 40 different varieties of mustard plants, but the three principal ones which also vary in colour are Brassica hirta or alba (yellow-white), Brassica nigra (black) and Brassica juncea (brown) (ElvinLewis, 2001). Mustard seeds can be traced to different areas of Europe and Asia with the yellow-white variety originating in the Eastern Mediterranean regions, the brown from the foothills of the Himalayas and the black from the Middle East. Mustard seeds, apart from being a culinary essential, have had medicinal applications dating back to the time of Hippocrates. It has in fact been once mentioned as the greatest herb ever. It has found application in cancer treatment and prevention, treatment of rheumatic arthritis, antiinflammation, asthma and migraine [Elvin-Lewis, 2001]. These and many more therapeutic potentials have been widely attributed to the presence of Selenium, Magnesium and Bcomplex vitamins as its major constituents [Billman, 2013]. It is however important to note that despite these widely acclaimed great healing properties of mustard seeds, information regarding safety and efficacy in pregnancy and lactation is lacking as well as some other forms of contraindications and interactions. Therein lays the rationale for this research with pregnancy and postnatal prefrontal cortex development being the focal point. The prefrontal cortex is the part of the brain responsible for executive functions/decisions as well as complex cognitive processes. The prefrontal cortex is primarily concerned with executive functions (Yang \& Raine, 2009). The executive functions of the frontal cortex involve the ability to recognize future consequences resulting from current actions, to choose between good and bad actions (or better and best), override and suppress unacceptable social responses, and determine similarities and differences between things or events (Yang \& Raine, 2009). Therefore, it is involved in higher mental functions. The frontal cortex also plays an important part in retaining longer term memories which are not task-based. These are often memories associated with emotions derived from input from the brain's limbic system. The frontal cortex modifies those emotions to generally fit socially acceptable norms (Anderson et al., 1999).

\section{MATERIALS AND METHODS}

\section{Animal Acquisition and Care}

All protocols and treatment procedures were done according to the Institutional Animal Care and Use Committee (IACUC) guidelines and as approved by the Faculty of Basic Medical Sciences Ethics Review Committee, University of Ilorin, Nigeria. Eighteen adult female rats weighing an average of $180 \pm 20 \mathrm{~g}$ were purchased from a private animal holding in Ilorin and used for the research. These rats were kept in the animal house of the faculty of Basic Medical Sciences, University of Ilorin. The rats were on a daily basis fed with rat pellets. They had access to tap water ad libitum. Acclimatization was for a period of fourteen days.

\section{Grouping}

The 18 adult female rats were split into 3 groups $(n=6)$ as shown in the table below:

Table 1: showing the groupings of the animals with their corresponding treatments, dosages, duration of administration and number of animals in each sub-group.

\begin{tabular}{|l|c|c|c|c|}
\hline \multicolumn{1}{|c|}{ Groups } & Treatment & Dosage & Duration & N \\
\hline Group A & Mustard extract & $200 \mathrm{mg} / \mathrm{kg}$ body weight & 12 days $(3-6,8-11,15-18)$ & 6 \\
\hline Group B & Mustard extract & $100 \mathrm{mg} / \mathrm{kg}$ body weight & 12 days $(3-6,8-11,15-18)$ & 6 \\
\hline
\end{tabular}




\begin{tabular}{|l|l|l|l|l|}
\hline Group C & Distilled water & $1 \mathrm{ml}$ & 12 days $(3-6,8-11,15-18)$ & 6 \\
\hline
\end{tabular}

\section{Purchase and Preparation of Extract}

Mustard seeds were obtained from a local merchant in Ilorin. It was certified true by the Department of Plant Biology at the University of Ilorin. The extract was prepared according to the method described by Inyang et al. [2014]. The mustard seeds (Brassica nigra) were pulverized into powder with an electric blender. Three hundred grams $(300 \mathrm{~g})$ of the ground seeds were soaked in $1000 \mathrm{ml}$ of distilled water; stirred and left for 72 hours in a refrigerator at $4^{\circ} \mathrm{C}$. The mixture was sieved and filtered with Whatman No.1 filter paper. The resultant filtrate was dried in a water bath at $40^{\circ} \mathrm{C}$ for 96 hours to get the concentrate which was then diluted to stock [Inyang et al., 2014].

\section{Administration}

Following mating of dams by stud males, and confirmation of pregnancy, the extract was administered to pregnant dams via the oral route. Proper volume was ensured through the use of a calibrated syringe fitted with an oral cannula.

\section{Sacrifice and Sample Collection}

Rat pups for experimental groups were sacrificed on postnatal days $1,7,14,21,28$, and 35 . The brains were excised with the use of brain forceps and weighed. The tissues were immersed in 4\% paraformaldehyde (PFA-PBS) for 24hrs and postfixed in same. They were subsequently put through routine histological and histochemical procedures of hematoxylin and eosin for general histological observation and Cresyl fast violet for Nissl substance. The prefrontal cortices of the animals were cut out with a scalpel using coordinates from the stereotaxic atlas of rat brain.

\section{Statistical Analysis}

All quantitative data were analyzed using GraphPad Prism ${ }^{\circledR}$ (version 6) and SPSS (version 20) software. Litter size, birth weight, brain weight outcomes were plotted in ANOVA followed with Tukey's multiple comparisons test. Significance was set at $p<0.05^{*} \quad(95 \%$ confidence interval). The results were represented in bar charts with error bars to show the mean and standard error of mean respectively.

\section{Average Litter Size of Gestation Group}

Upon delivery, the litter size was determined. This was evaluated as the total number of pups in the litter, dead or alive. Control group had more average number of litters than the $100 \mathrm{mg} / \mathrm{kg}$ body weight treated group. This was significant statistically at $p<0.05$. Many pups from the $100 \mathrm{mg} / \mathrm{kg}$ body weight treated group didn't survive past the first week of parturition. There was significant difference $(p<0.05)$ between litter size of dams that received the $100 \mathrm{mg} / \mathrm{kg}$ body weight treatment and dams that received distilled water. The group that received $200 \mathrm{mg} / \mathrm{kg}$ body weight treatment had spontaneous abortions, hence no litters were obtained.

\section{Phenotypical Observation}

The pups were checked after determination of litter size for deformities. No obvious

\section{RESULTS}

malformations were observed in both control and treated groups. However, the pups of treated group had a paler pink colour when compared to those of the control group.

\section{Infant Birth Weight}

There was no significant difference $(p>0.05)$ in birth weight of pups in the $100 \mathrm{mg} / \mathrm{kg}$ body weight treated rats and the control rats. The $200 \mathrm{mg} / \mathrm{kg}$ body weight group had no parturition.

\section{Infant Brain Weight (Postnatal day1)}

The brain weight of pups from control and treated groups were compared. Since there was no littering from the $200 \mathrm{mg} / \mathrm{kg}$ body weight group, the brain weight of the group was not put into consideration. There was no statistically significant difference between the mean brain weights of pups in the treated group versus the control group at postnatal day one (PND 1). 


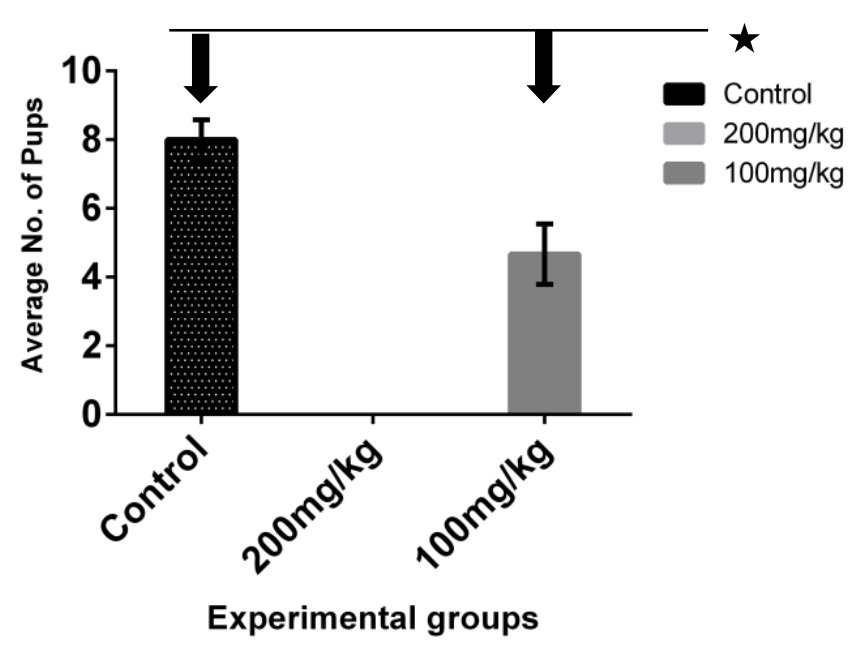

Figure 1: Bar Graph Showing the Average No. of Pups per Group $(*=p<0.05)$.

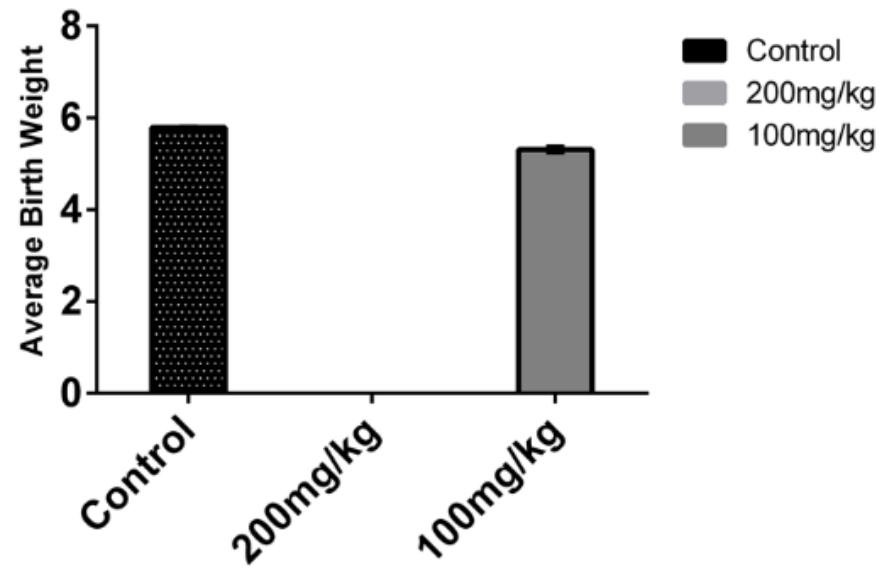

Experimental groups

Figure 2: Bar Graph Showing the Average Birth Weight of Pups in the Control a nd Treated Groups $(*=p<0.05)$.

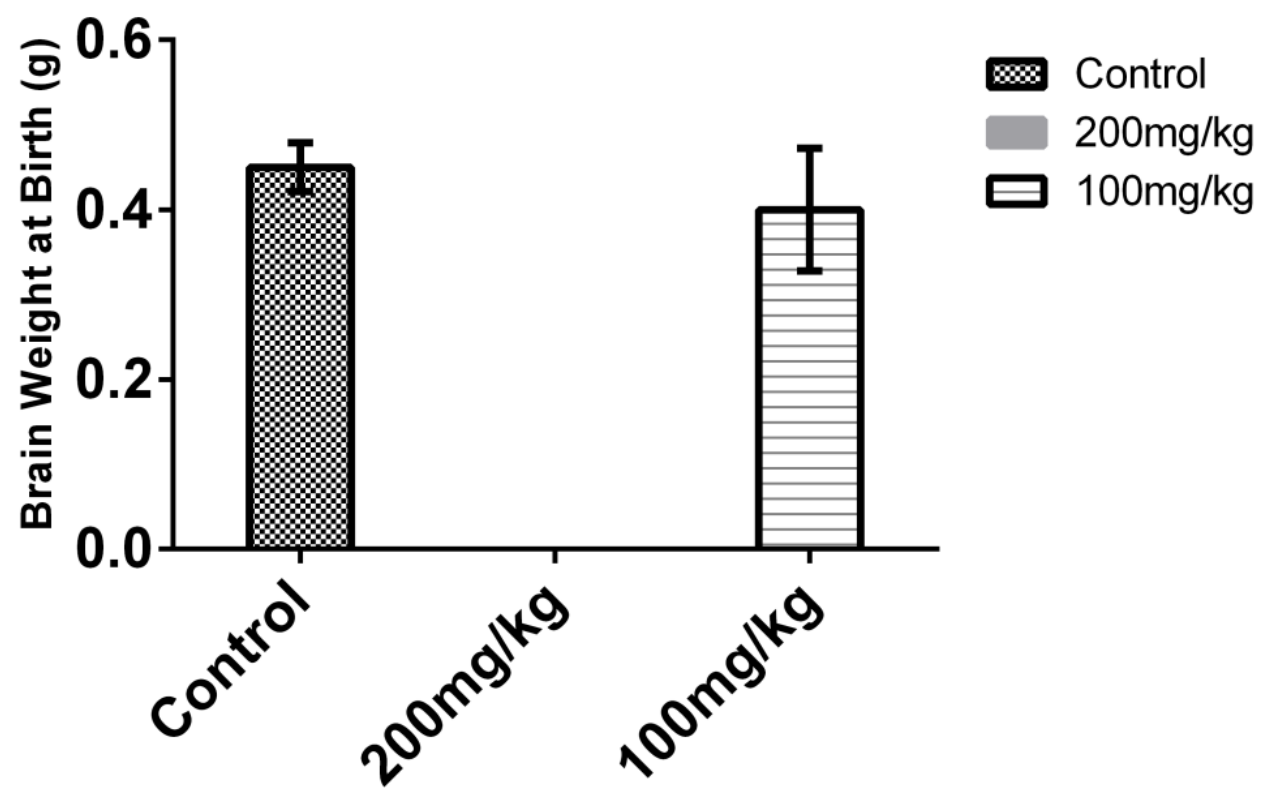

\section{Experimental groups}

Figure 3: Chart Showing the Brain Weight of Pups of the different groups at Postnatal Day1 $(p<0.05)$. 


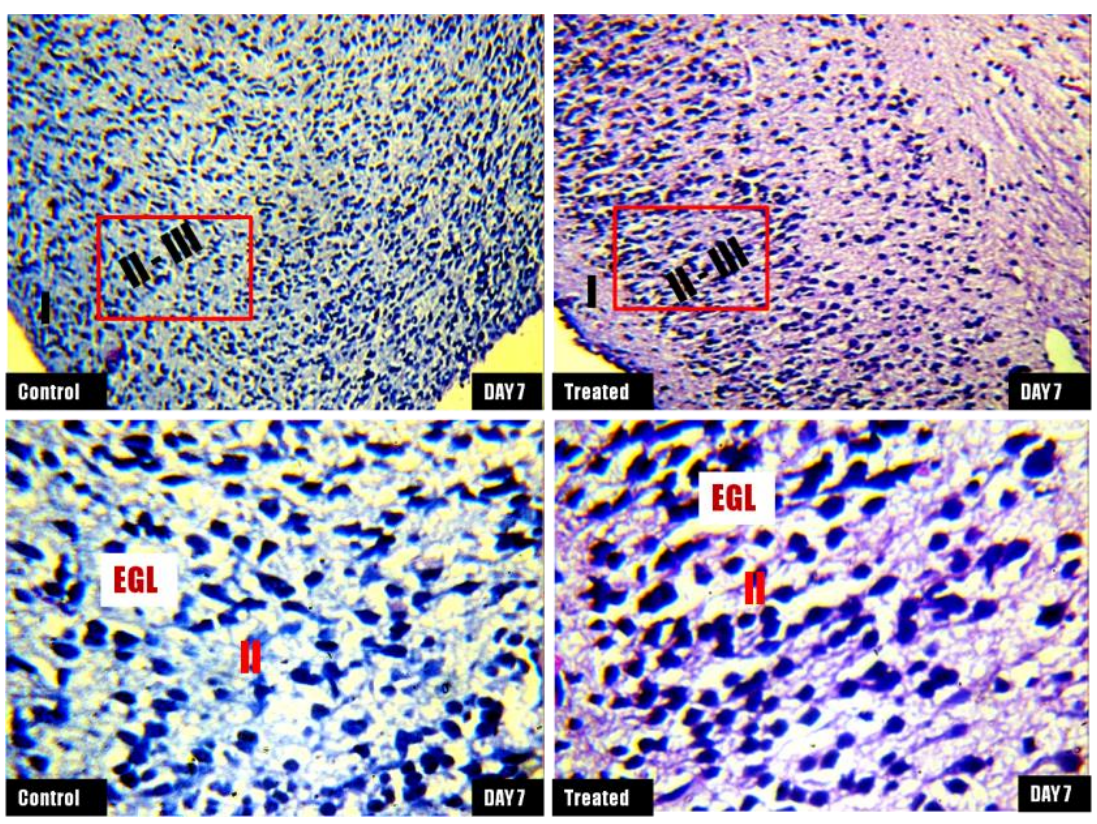

Figure 4: Representative light micrographs of the lateral prefrontal cortex of postnatal day 7 rats in the control and $100 \mathrm{mg} / \mathrm{kg}$ Brassica nigra extract treated groups showing superficial cortical layers (layers I, II and III). Small pyramidal and stellate cells are shown in the external granular layer (EGL) red box signifies magnified portion of the slide. H\&E stain: Top layer X100 and Bottom layer X400.
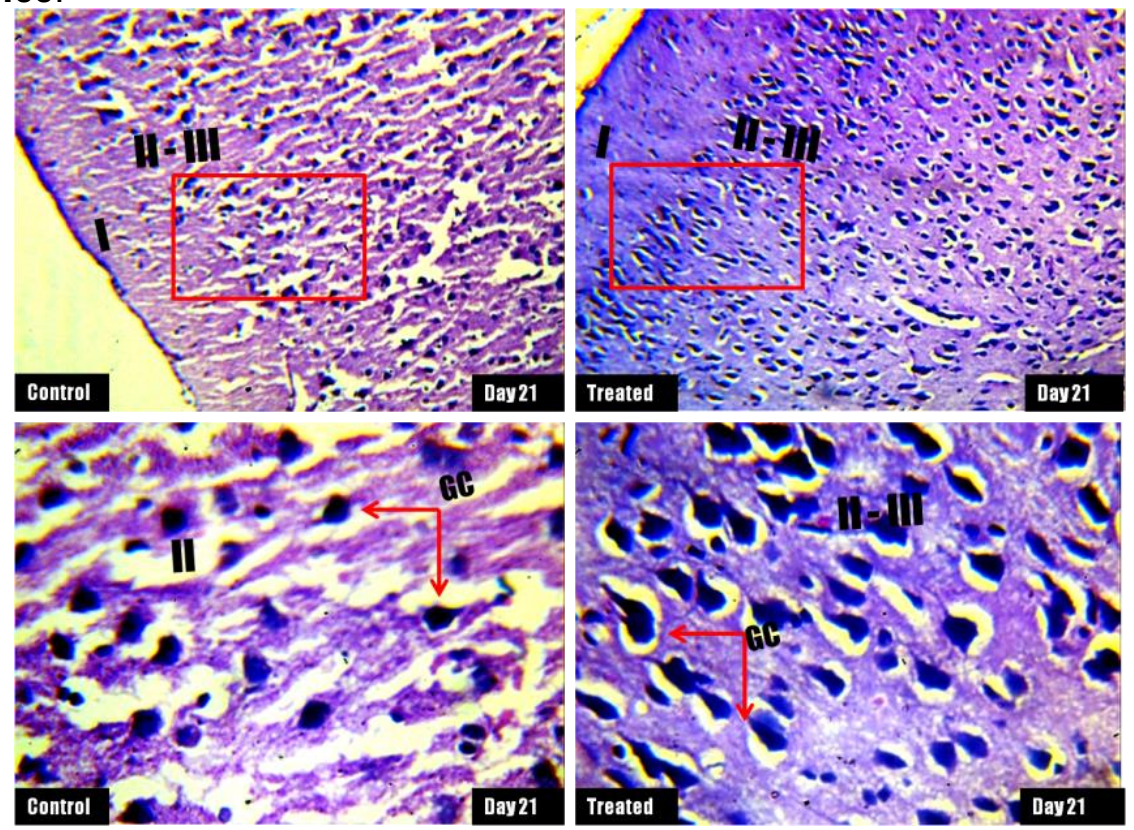

Figure 5: Representative light micrographs of the lateral prefrontal cortex of postnatal day 21 rats in the control and $100 \mathrm{mg} / \mathrm{kg}$ Brassica nigra extract treated group showing superficial cortical layers (layers I, II and III). Red box shows magnified portion of the external granular layer, Red Arrow = Neuronal Cell. H\&E stain: Top layer (X100); Bottom layer (X400). 


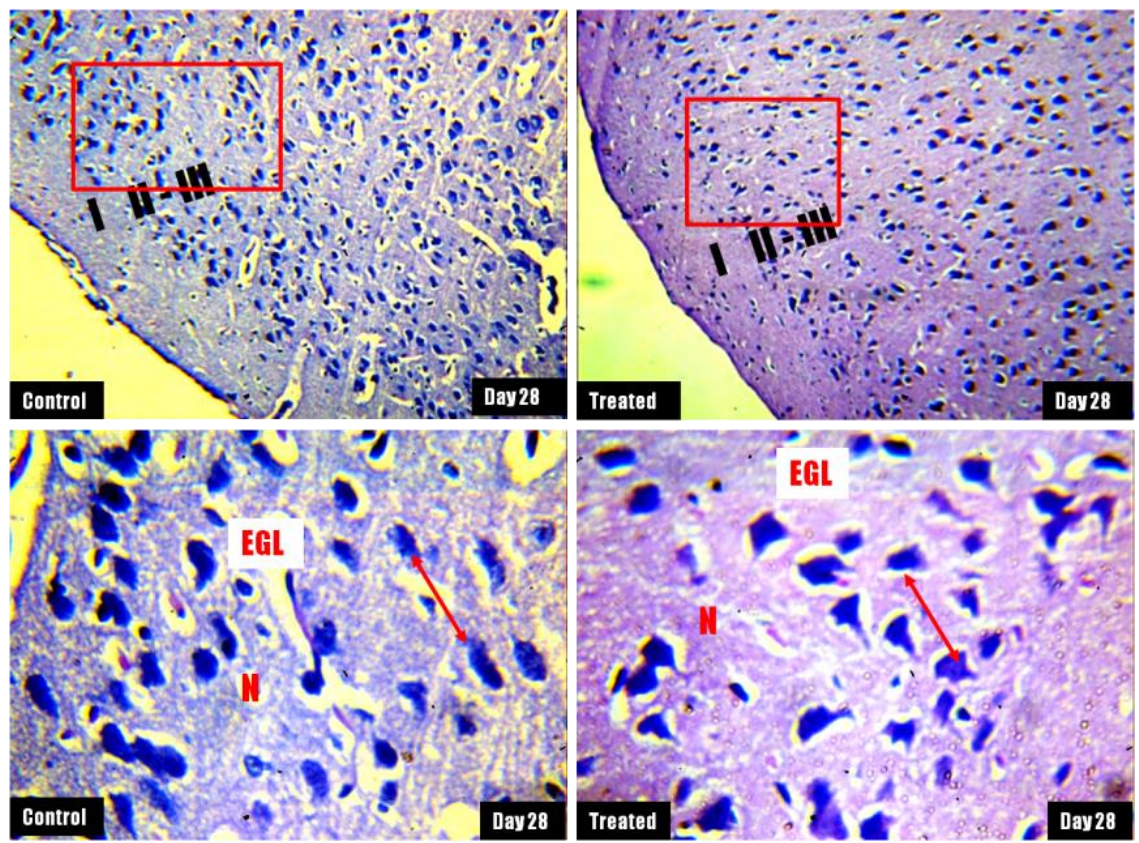

Figure 6: Representative light micrographs of the lateral prefrontal cortex of postnatal days 28 rats in the control group versus $100 \mathrm{mg} / \mathrm{kg}$ Brassica nigra extract treated group showing superficial cortical layers (layers I, II and III). Small-sized pyramidal cells (red arrow) are shown in the external granular layer (EGL), N = Neuropil. H\&E stain X100 (Top layer) and X400 (Bottom layer).
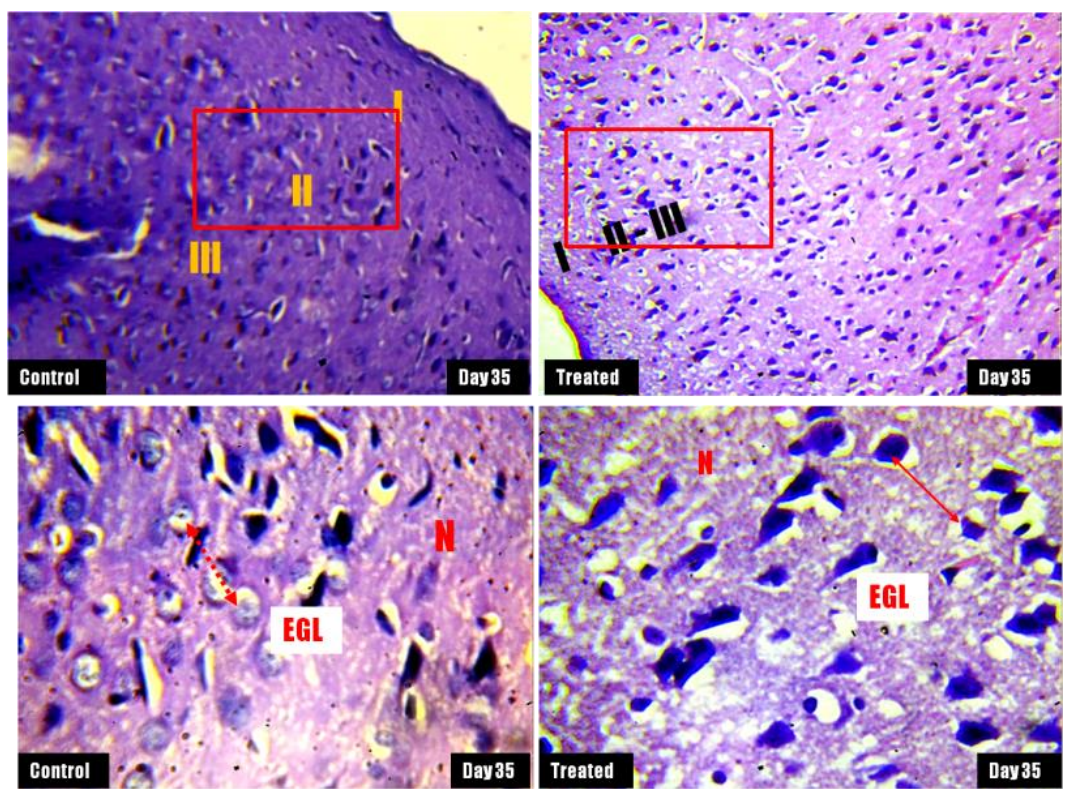

Figure 7: Representative light micrographs of the lateral prefrontal cortex of postnatal day 35 rats in the control group versus $100 \mathrm{mg} / \mathrm{kg}$ Brassica nigra extract treated group showing superficial cortical layers (layers I, II and III). Small-sized pyramidal cells and granule cells (unbroken red arrow) are shown in the external granular layer (EGL), $\mathrm{N}=$ Neuropil. H\&E stain X100 (Top layer) and X400 (Bottom layer). 

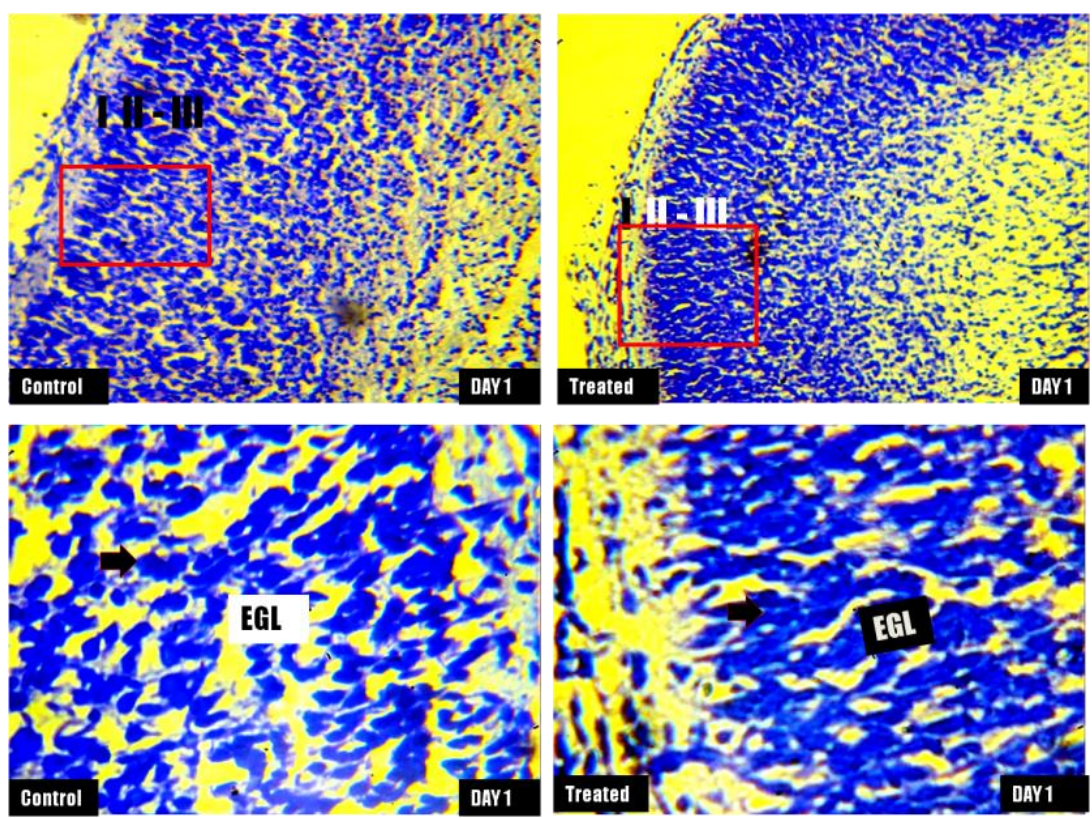

Figure 8: Representative light micrographs of the lateral prefrontal cortex of postnatal days 1 rats in the control group versus $100 \mathrm{mg} / \mathrm{kg} \mathrm{Brassica} \mathrm{nigra} \mathrm{extract} \mathrm{treated} \mathrm{group} \mathrm{showing} \mathrm{superficial} \mathrm{cortical} \mathrm{layers} \mathrm{(layers} \mathrm{I,} \mathrm{II} \mathrm{and} \mathrm{III).} \mathrm{Small-sized} \mathrm{pyramidal}$ cells (thick black arrows) are shown in the external granular layer (EGL). CFV stain: X100 (Top layer) and X400 (Bottom layer).
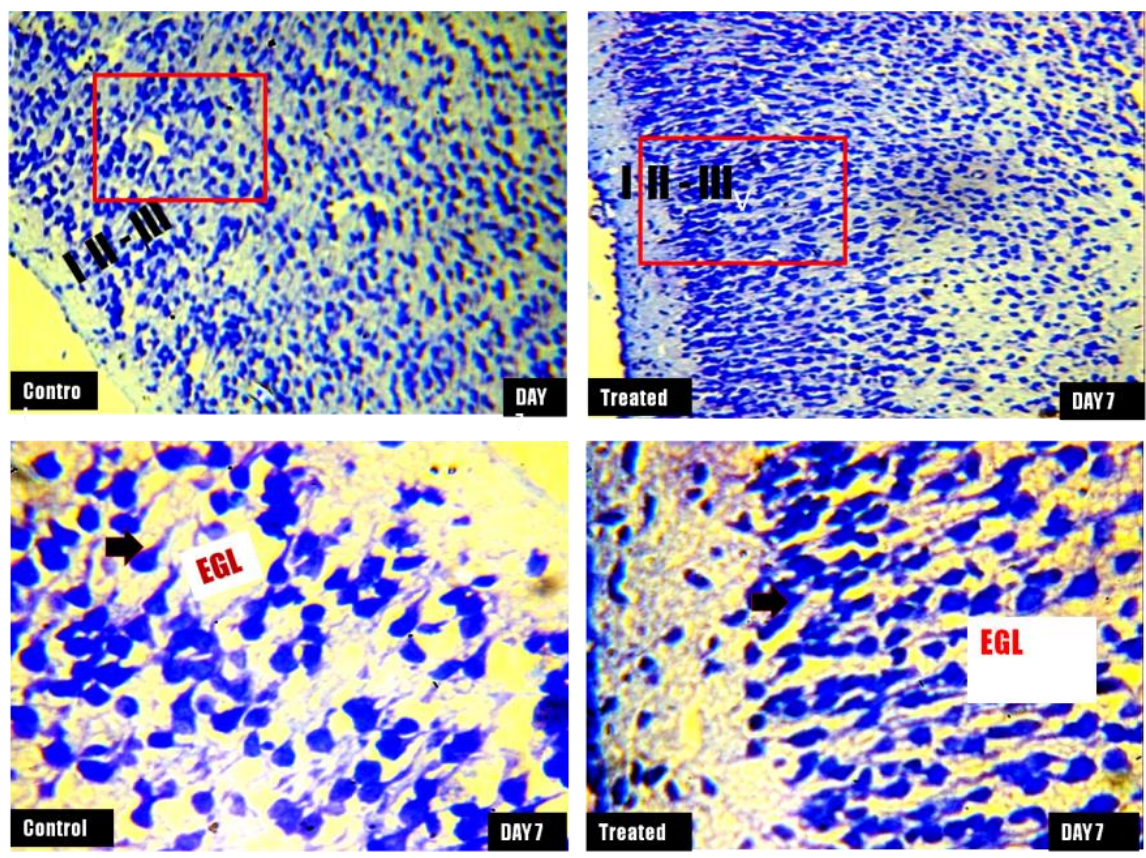

Figure 9: Representative light micrographs of the lateral prefrontal cortex of postnatal day 7 rats in the control group versus $100 \mathrm{mg} / \mathrm{kg}$ Brassica nigra extract treated group showing superficial cortical layers (layers I, II and III). Small-sized pyramidal cells (thick black arrow) are shown in the external granular layer (EGL), red box shows magnified portion of the micrograph. CFV stain: X100 (Top layer) and X400 (Bottom layer). 

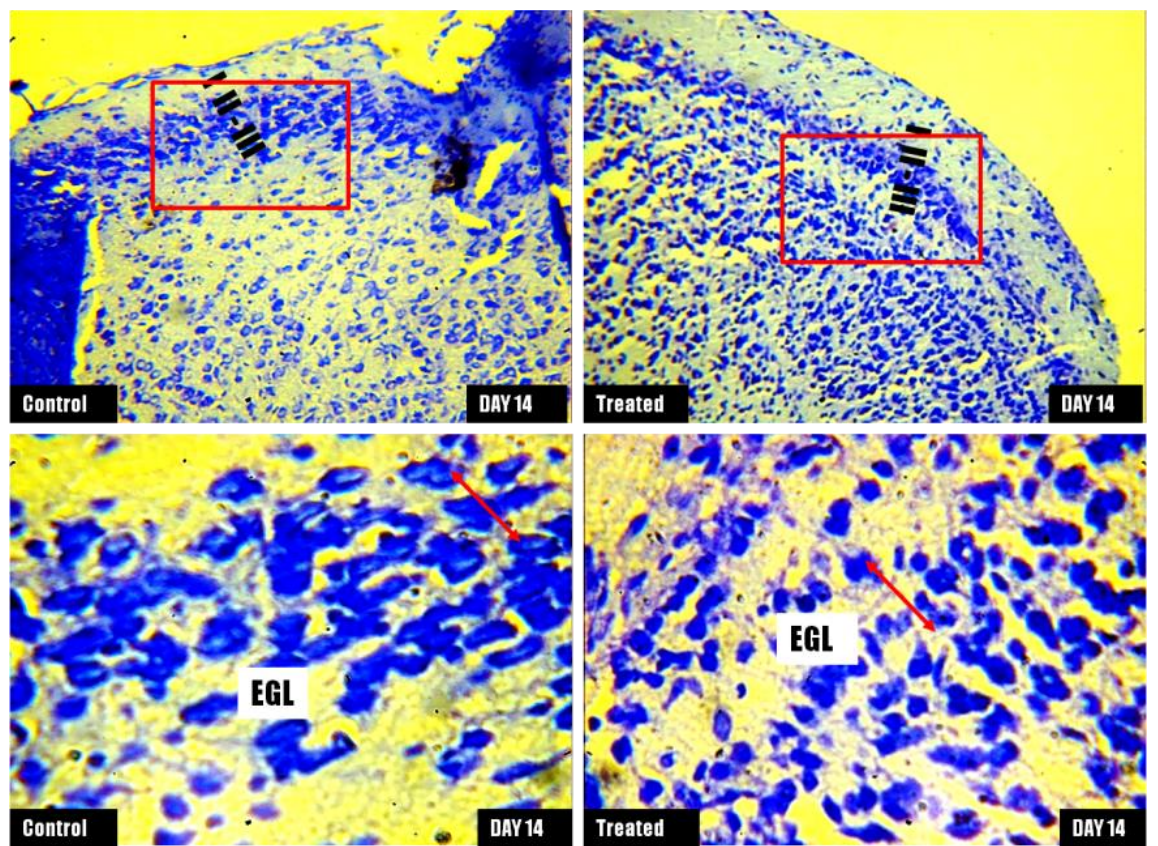

Figure 10: Representative light micrographs of the lateral prefrontal cortex of postnatal day 14 rats in the control group versus $100 \mathrm{mg} / \mathrm{kg}$ Brassica nigra extract treated group showing superficial cortical layers (layers I, II and III). Small-sized pyramidal cells are shown in the external granular layer (EGL) red box shows magnified portion of micrograph. CFV stain: X100 (Top layer) and X400 (Bottom layer).

Figure 11.
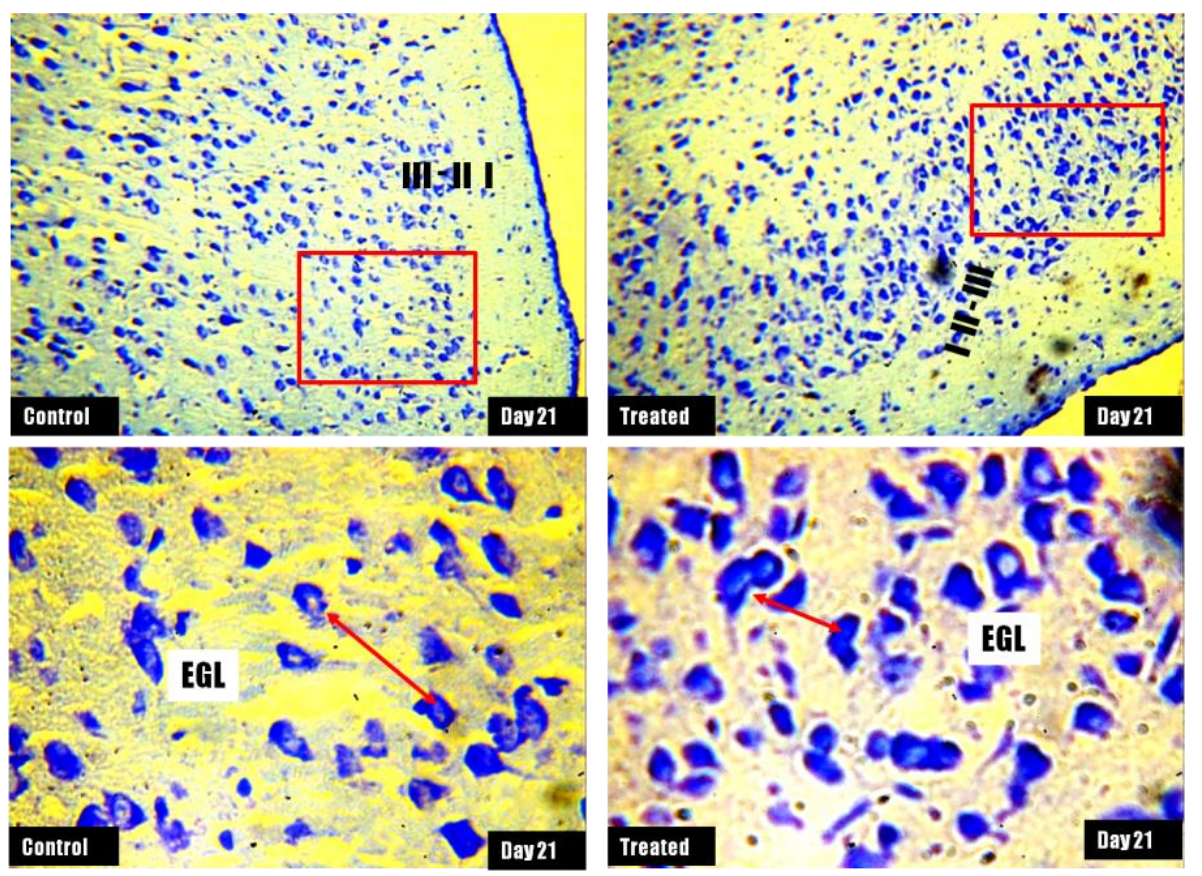

Figure 11: Representative light micrographs of the lateral prefrontal cortex of postnatal day 21 rats in the control group versus $100 \mathrm{mg} / \mathrm{kg} \mathrm{Brassica} \mathrm{nigra} \mathrm{extract} \mathrm{treated} \mathrm{group} \mathrm{showing} \mathrm{superficial} \mathrm{cortical} \mathrm{layers} \mathrm{(layers} \mathrm{I,} \mathrm{II} \mathrm{and} \mathrm{III).} \mathrm{Small-sized} \mathrm{pyramidal}$ cells are shown in the external granular layer (EGL). CFV stain: X100 (Top layer) and X400 (Bottom layer). 


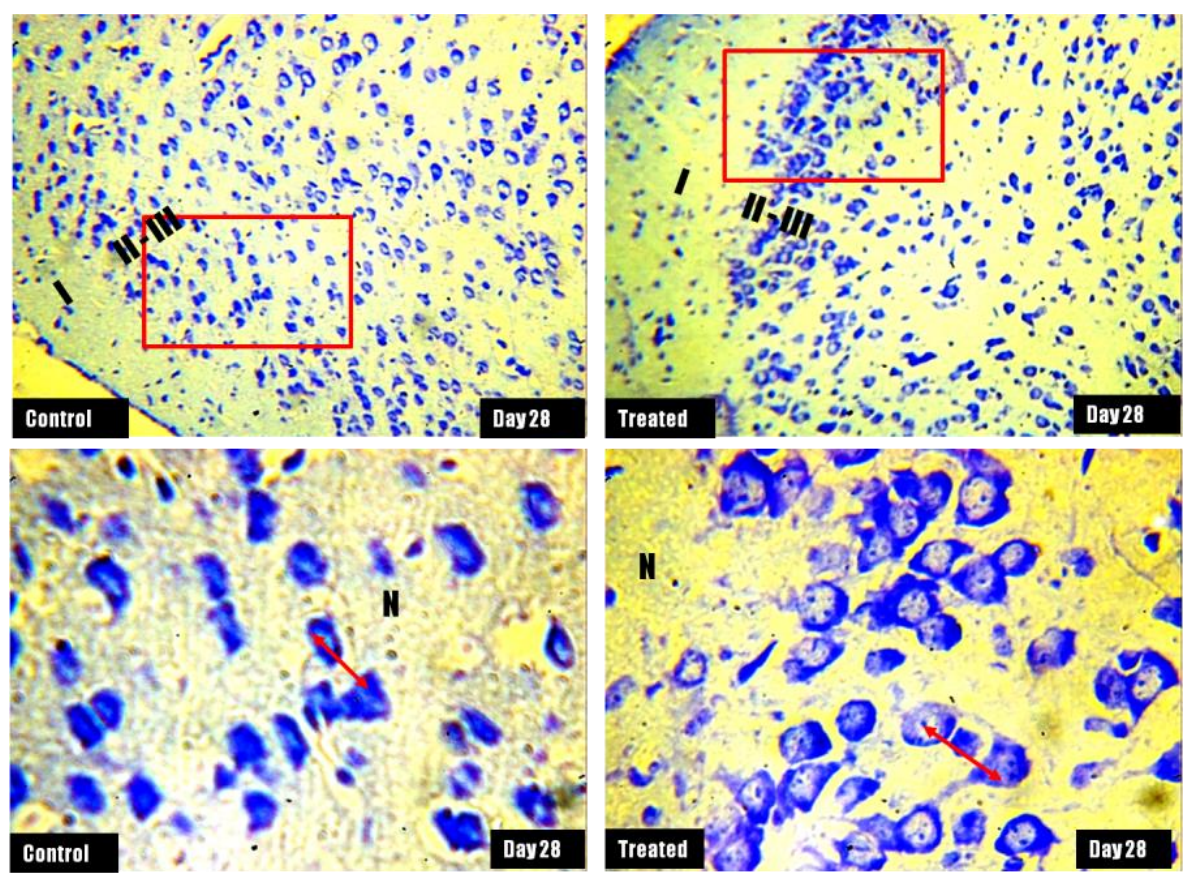

Figure 12: Representative light micrographs of the lateral prefrontal cortex of postnatal day 28 rats in the control group versus $100 \mathrm{mg} / \mathrm{kg}$ Brassica nigra extract treated group showing superficial cortical layers (layers I, II and III). Small-sized pyramidal cells (red arrows) are shown in the external granular layer (EGL), $N$ = neuropil. CFV stain: X100 (Top layer) and X400 (Bottom layer).

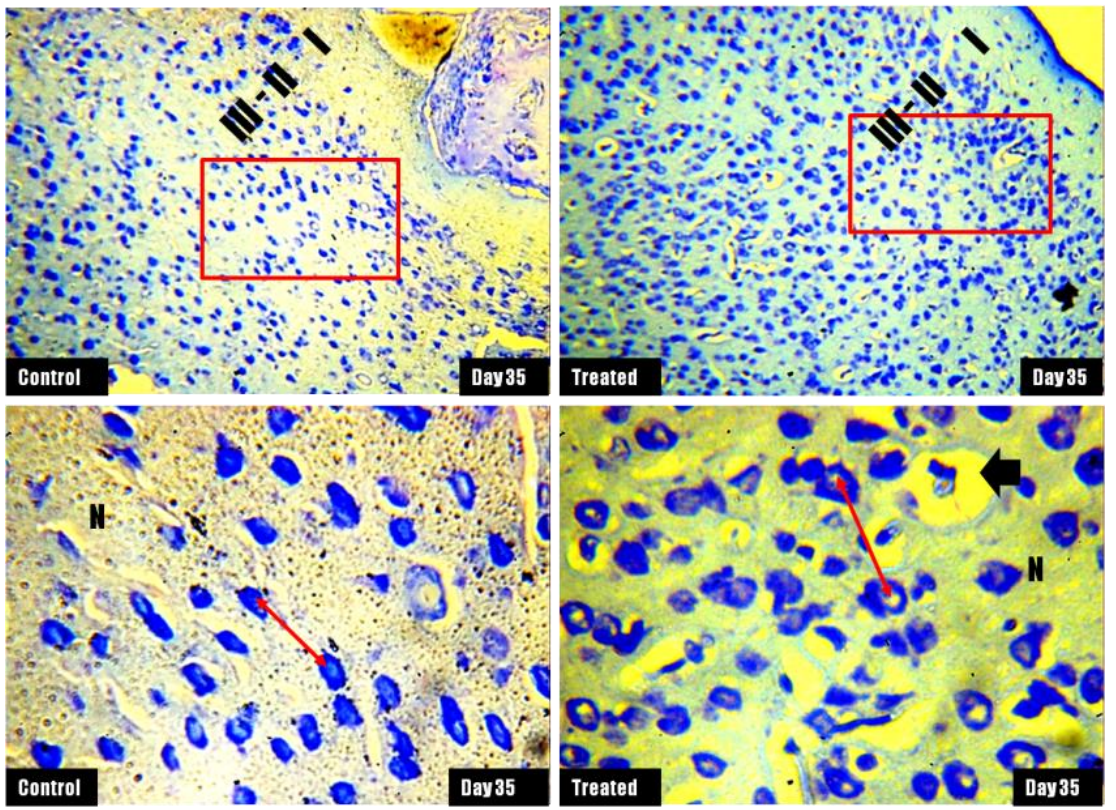

Figure 13: Representative light micrographs of the lateral prefrontal cortex of postnatal day 35 rats in the control group versus $100 \mathrm{mg} / \mathrm{kg}$ Brassica nigra extract treated group showing superficial cortical layers (layers I, II and III). Small-sized pyramidal cells (red arrows) are shown in the external granular layer (EGL), $\mathrm{N}=$ neuropil, thick black arrow = vacuolation. CFV stain: X100 (Top layer) and X400 (Bottom layer).

\section{DISCUSSION}

We had in an earlier study investigating the dose-dependent effects of black mustard seeds' extract on the prefrontal cortices of adult Wistar rats, seen the appetite-stimulating character of mustard seeds, as animals which received the administration ate more and consequently, had 
a statistically significant increase in body weight relative to the control [Arogundade et al., 2017]. Kumar et al. in consonance, reported an increased weight gain in animals treated with Brassica nigra oil at $500 \mathrm{mg} / \mathrm{kg}$ and $1000 \mathrm{mg} / \mathrm{kg}$ when compared with the control in their experiment assessing the antihyperglycemic and antioxidant activity of Brassica nigra oil in streptozotocin-induced diabetic rats [Kumar et al., 2013]. There was however, no significant difference in the mean birth weights of exposure groups. Together with, in the same study, we explored the effects of varying doses of the extract on neurobehaviour and found that at a dose of $200 \mathrm{mg} / \mathrm{kg}$, correct spontaneous alternation was significantly altered [Arogundade et al., 2017]. This research aimed to examine the effects of crude aqueous Brassica nigra seeds extract at two different doses $(200 \mathrm{mg} / \mathrm{kg}$ and $100 \mathrm{mg} / \mathrm{kg})$ on gestation and postnatal neurodevelopment. Our first point of call was in comparing litter size of the experimental groups. Upon delivery, the litter size was determined. This was evaluated as the total number of pups in the litter, dead or alive. Control group had more average number of litters than the $100 \mathrm{mg} / \mathrm{kg}$ body weight treated group. This was significant statistically at $\mathrm{p}<0.05$. Many pups from the $100 \mathrm{mg} / \mathrm{kg}$ body weight treated group however, didn't survive past the first week of parturition. There was significant difference $(p<0.05)$ between litter size of dams that received the $100 \mathrm{mg} / \mathrm{kg}$ body weight treatment and dams that received distilled water. Animals that received $200 \mathrm{mg} / \mathrm{kg}$ body weight treatment of the extract had abortions in the first and second trimesters of pregnancy, hence no litters were obtained. Although the mechanism through which it exerts its abortifacient property we do not yet fully understand, it is without doubt that Brassica nigra interfered with developmental process at the administered dose of $200 \mathrm{mg} / \mathrm{kg}$ body weight and most notably at the second trimester of gestation.

The pups were checked after determination of litter size for signs of deformities. No obvious malformations were observed in both control and treated group of $100 \mathrm{mg} / \mathrm{kg}$ body weight. However, the pups of the $100 \mathrm{mg} / \mathrm{kg}$ body weight treated group had a paler pink colour when compared to those of the control group. Asides that, no developmental anomaly was apparent. There was no significant difference $(p<0.05)$ in the mean birth weight of pups from the $100 \mathrm{mg} / \mathrm{kg}$ body weight treated rats when compared with those from the control group. The $200 \mathrm{mg} / \mathrm{kg}$ body weight group had no parturition; therefore, there was no birth weight to evaluate. The brain weight of pups from control and treated groups were compared. Since there was no littering from the $200 \mathrm{mg} / \mathrm{kg}$ body weight group, the brain weight of the group was not put into consideration. There was no statistically significant difference between the mean brain weights of pups in the treated group versus the control group at postnatal day one. Histological observation of the prefrontal cortices of animals whose mothers received the treatment, revealed no visible distortions when compared with the control. The cells appeared comparable with the ones from animals in the control group at day $1,7,14, \& 21$. On days 28 \& 35 however, affinity for Nissl stain was low. In our earlier study on the prefrontal cortices of adult Wistar rats, we reported presence of apoptotic bodies in PFC microanatomy of treated adult rats as well as a reduction in the staining intensity across all Brassica nigra-treated groups when compared with the control [Arogundade et al., 2017]. However, from the observations of similarity in neuronal morphology and protein affinity (through Nissl staining), we cannot conclusively say that PFC cells of these young rats are absolutely normal. While no alterations in PFC microanatomy are immediately apparent, it would be far-fetched to say that the elicitation of structural and functional isms in cells, tissues, and nervous organ-system are impossible. We did not explore the epigenetic pathway through assay for changes in epigenetic regulators (DNA methylation and posttranslational modifications of histone tails). These processes have been shown to play a fundamental role in embryonic development, cell differentiation, and maintenance of cellular identity [MartinSubero, 
2011]. It would not be surprising to see Brassica nigra exerting epigenetic properties through Latent Early-life Associated Regulation (LEARn).

In conclusion, Brassica plants are highly regarded for their nutritional value and potent healing properties. It is however imperative to ensure that the general health of the community, especially of pregnant women in not

Conflict of Interests: The authors declare no competing interests.

Funding: This research did not receive any specific grant from funding agencies in the public, commercial, or not-for-profit sectors.

\section{REFERENCES}

1. Andersen SL. 2003. Trajectories of brain development: Point of vulnerability or window of opportunity? Neurosci. Biobehav. Rev.27:3-18.

2. Anderson SW, Bechara A, Damasio H, Tranel D, \& Damasio AR. 1999. "Impairment of social and moral behavior related to early damage in human prefrontal cortex". Nature Neuroscience 2 (11): 1032-1037.

3. Arogundade TT, Enaibe BU, Adigun OO, Adigun FM, Gbadamosi IT. 2017. Dose-dependent Effect of Black Mustard Seeds (Brassica nigra) Extract on the Prefrontal Cortex of Adult Wistar Rats. Anatomy. 11(3):107-114.

4. Bellani M, Baiano M, Brambilla P. 2011. Brain anatomy of major depression II. Focus on amygdala. Epidemiol Psychiatr Sci. 20:33-36.

5. Billman GE. 2013. The effects of omega-3 polyunsaturated fatty acids on cardiac rhythm; a critical assessment. Pharmacology and Therapy, 140(1), $53-80$.

6. Elvin-Lewis M. 2001. Should we be concerned about herbal remedies? Journal of Ethnopharmacology, 75(2- 3),141 - 164.

7. Gilbertson MW, Shenton ME, Ciszewski A, Kasai K, Lasko NB, Orr SP, Pitman RK. 2002. Smaller hippocampal volume predicts pathologic vulnerability to psychological trauma. Nat. Neurosci. 5: $1242-1247$.

8. Gluckman PD, Hanson MA. 2004. Living with the past: Evolution, development, and patterns of disease. Science. 305:1733-1736.

9. Inyang IJ, Eyo AO, Olajide TM, Essien A. 2014. Effects of Ethanolic Extract of Brassica juncea (Brown Mustard) on the Brain and Kidney Tissues of Albino Wistar Rats. Journal of Biology, Agriculture, and Healthcare. ISSN 2224-3208 (paper) Vol. 4, No. 22.

10. Kumar M, Sharma S, Vasudeva N. 2013. In Vivo Assessment of Antihyperglycemic and Antioxidant Activity from Oil of Seeds of Brassica nigra in Streptozotocin-Induced Diabetic Rats. Advanced Pharmaceutical Bulletin, 3(2), 359-365.

11. MartínSubero JI. 2011. How epigenomics brings phenotype into being. Pediatr. Endocrinol. Rev. S1, 506-510.

12. Siegler R. 2006. How Children Develop, Exploring Child Develop Student Media Tool Kit \& Scientific American Reader to Accompany How Children Develop. New York: Worth Publishers. ISBN 0716761130.

13. Swanson JD, Wadhwa PM. 2008. Developmental origins of child mental health disorders. J. Child Psychol. Psychiatry. 49:1009-1019.

14. Yang Y, Raine A. 2009. Prefrontal structural and functional brain imaging findings in antisocial, violent, and psychopathic individuals: a meta-analysis. Psychiatry Res. 174, $81-88$. 